\title{
The $I a-2 \beta$ intronic miRNA, miR-153, is a negative regulator of insulin and dopamine secretion through its effect on the Cacnalc gene in mice
}

\author{
Huanyu Xu ${ }^{1}$ - Liron Abuhatzira ${ }^{1}$ - Gilberto N. Carmona ${ }^{1}$ - Suryakiran Vadrevu ${ }^{2}$. \\ Leslie S. Satin ${ }^{2}$ - Abner L. Notkins ${ }^{1}$
}

Received: 30 December 2014 / Accepted: 11 June 2015 / Published online: 4 July 2015

(C) Springer-Verlag (outside the USA) 2015

\begin{abstract}
Aims/hypothesis miR-153 is an intronic miRNA embedded in the genes that encode $I A-2$ (also known as $P T P R N$ ) and $I A-2 \beta$ (also known as PTPRN2). Islet antigen (IA)-2 and IA-2 $\beta$ are major autoantigens in type 1 diabetes and are important transmembrane proteins in dense core and synaptic vesicles. miR-153 and its host genes are co-regulated in pancreas and brain. The present experiments were initiated to decipher the regulatory network between miR-153 and its host gene $I a-2 \beta$ (also known as Ptprn2).

Methods Insulin secretion was determined by ELISA. Identification of miRNA targets was assessed using luciferase assays and by quantitative real-time PCR and western blots in vitro and in vivo. Target protector was also employed to evaluate miRNA target function.

Results Functional studies revealed that miR-153 mimic suppresses both glucose- and potassium-induced insulin secretion (GSIS and PSIS, respectively), whereas miR-153 inhibitor enhances both GSIS and PSIS. A similar effect on dopamine secretion also was observed. Using miRNA target prediction software, we found that miR-153 is predicted to target the
\end{abstract}

Electronic supplementary material The online version of this article (doi:10.1007/s00125-015-3683-8) contains peer-reviewed but unedited supplementary material, which is available to authorised users.

Abner L. Notkins

anotkins@dir.nidcr.nih.gov

Experimental Medicine Section, Laboratory of Sensory Biology, National Institute of Dental and Craniofacial Research, National Institutes of Health, 9000 Rockville Pike, Bethesda, MD 20892, USA

2 Brehm Diabetes Research Center, University of Michigan Medical School, Ann Arbor, MI, USA
3'UTR region of the calcium channel gene, Cacnalc. Further studies confirmed that Cacnalc mRNA and protein are downregulated by miR-153 mimics and upregulated by miR-153 inhibitors in insulin-secreting freshly isolated mouse islets, in the insulin-secreting mouse cell line MIN6 and in the dopamine-secreting cell line PC12.

Conclusions/interpretation miR-153 is a negative regulator of both insulin and dopamine secretion through its effect on Cacnalc expression, which suggests that IA- $2 \beta$ and miR-153 have opposite functional effects on the secretory pathway.

Keywords Cav1.2 $\cdot$ IA-2 2 Insulin secretion $\cdot$ Intronic miRNA · MicroRNAs

$\begin{array}{ll}\text { Abbreviations } \\ \text { CACNA1C } & \begin{array}{l}\text { Calcium channel voltage-dependent, L type, } \\ \end{array} \\ & \alpha 1 \mathrm{C} \text { subunit } \\ \text { DCV } & \text { Dense core vesicle } \\ \text { DKO } & \text { Ia-2/Ia-2 } \beta \text { double knockout } \\ \text { GSIS } & \text { Glucose-stimulated insulin secretion } \\ \text { IA } & \text { Islet antigen } \\ \text { Ia-2 KO } & \text { Ia-2 knockout mice } \\ \text { Ia-2 } \beta \text { KO } & \text { Ia-2 } \beta \text { knockout mice } \\ \text { miRNA } & \text { MicroRNA } \\ \text { NIDCR } & \text { National Institute of Dental and Craniofacial } \\ & \text { Research } \\ \text { PMA } & \text { Phorbol-12-myristate-13-acetate } \\ \text { PSIS } & \text { Potassium-stimulated insulin secretion } \\ \text { PTP } & \text { Protein tyrosine phosphatase } \\ \text { TP } & \text { Target protector } \\ \text { VDCC } & \text { Voltage-dependent calcium channels } \\ \text { WT } & \text { Wild-type }\end{array}$




\section{Introduction}

Islet antigen (IA)-2 and IA- $2 \beta$ are major autoantigens in type 1 diabetes [1]. Previous studies have shown that they are integral transmembrane proteins of dense core vesicles (DCVs) and/or synaptic vesicles $[2,3]$. IA- 2 and IA- $2 \beta$ are widely expressed in neuroendocrine cells throughout the body (e.g. pancreatic islets, brain, adrenals and gastrointestinal cells) [2-5]. They are members of the transmembrane protein tyrosine phosphatase (PTP) family and are enzymatically inactive with standard PTP substrates owing to two critical amino acid substitutions in the PTP domain. However, recent studies suggest that IA-2 $\beta$ may have low phosphatidylinositol phosphatase activity [6]. IA-2 and IA-2 $\beta$ have been found to play important roles in the secretion of hormones and neurotransmitters such as insulin, luteinising hormone (LH) and follicular stimulating hormone (FSH), noradrenaline (norepinephrine, NE), dopamine, serotonin and renin, and reduction of these hormones results in glucose intolerance, female infertility, behavioural changes and loss of circadian rhythm [3, 7-14].

Recently, we showed that the microRNA, miR-153, is embedded in intron 19 of both $I A-2$ (also known as PTPRN and $I C A 512$ ) and IA-2 $\beta$ (also known as PTPRN2) in humans and encodes two identical mature sequences (miR-153-1 and miR-153-2) [15]. In contrast, in the mouse and rat, miR-153

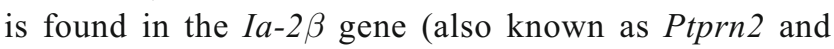
phogrin). The miR-153 precursor gives rise to two miRNA sequences, miR-153-3p and miR-153-5p, of which only miR$153-3 p$ is identical to the human miR-153-2 and is highly conserved, evolutionarily, across different species [15].

It is estimated that $\sim 37 \%$ of mammalian miRNAs are located within introns of protein coding genes [16], and coregulation of these intragenic miRNAs and their host genes is a common biological phenomenon $[15,17]$. Moreover, intronic miRNAs and their host genes, often tend to work in parallel, forming regulatory relationships between host genes and intronic miRNAs [18]. Based on the function of its host gene, $I a-2 \beta$, miR-153 is potentially linked to the secretion of hormones and neurotransmitters. Moreover, in a recent study we showed that in $I a-2 \beta$ knockout mice, miR-153 is at least partly co-regulated with its host gene, Ia-2 $\beta$ [15]. However, the exact relationship between IA-2 $\beta$, miR-153, and its target genes remains unclear. The present study was initiated to assess the functional effect of miR-153 on hormone and neurotransmitter secretion and to further our understanding of the relationship between the host gene $I a-2 \beta$, its intronic miR- 153 and the gene targets of miR-153.

\section{Methods}

Mice Targeted disruption of the individual $I a-2$ and $I a-2 \beta$ genes (Ia-2 KO and $I a-2 \beta \mathrm{KO})$ and generation of
$I a-2^{-/} / I a-2 \beta^{-/}$double knockout (DKO) mice have been described previously $[7,15]$. Animals used in this study were from C57/BL6 background and produced in our institute animal core facility (National Institute of Dental and Craniofacial Research [NIDCR], Bethesda, MD, USA). Lights were on from 06:00 to 18:00 and food and water were available ad libitum. All tissue samples harvested for this study were from age and sex-matched mice that were randomly selected from their home cage. Animal studies were conducted under protocols approved by the Institutional Animal Care and Use Committees of the National Institutes of Health (NIH), USA.

Cell lines The MIN6 cell line, 293T cell line and PC12 cells culture methods are described in detail in the Electronic Supplementary Material (ESM) Methods.

Mouse islets Islets from 3-4 month old sex-matched mice were isolated with slight modifications of the Collagenase P (Roche, Indianapolis, IN, USA) manufacturer's protocol. See ESM Methods for further details.

Bioinformatics analysis of potential miR-153 targets Identification of putative target genes of miR-153 was performed by two bioinformatics software programs, Targetscan 6.2 (www.targetscan.org/vert_61/, release 6.2, accessed 28 February 2013) and Pictar (http://pictar.mdc-berlin.de/, accessed 28 February 2013). We searched for miR-153 targets using the term 'calcium'. Overlap of miR-153 putative target genes by these two software programs were selected for further analysis.

MicroRNA mimic and inhibitor transfection MIN6 cells, mouse islets and PC12 cells were transfected with a miR-153 mimic or inhibitor (Qiagen, Germantown, MD, USA) or scramble control (AllStars Negative Control siRNA, Qiagen), using HiPerFect Transfection Reagent (Qiagen) according to the manufacturer's instructions. After $72 \mathrm{~h}$, the transfected cells were further processed for glucose- or potassiumstimulated insulin secretion (GSIS or PSIS, respectively), gene expression analyses or western blotting. For further details, see ESM Methods.

GSIS or PSIS Insulin secretion in MIN6 cells and mouse islets was measured after the cells were transfected as described above. Fold change of insulin secretion was calculated by comparing insulin levels before and after stimulation. For further details, see ESM Methods.

Dopamine secretion test The dopamine secretion test in PC12 cells was conducted at $72 \mathrm{~h}$ after transfection with miR-153 mimic, miR-153 inhibitor or control. Fold change of dopamine secretion was calculated by comparing dopamine levels before and after stimulation with high $\mathrm{K}^{+}$solution with 
or without phorbol-12-myristate-13-acetate (PMA). For further details, see ESM Methods.

Total RNA, miRNA and quantitative PCR Total RNA and miRNA were extracted using a miRNeasy Mini kit (Qiagen) following manufacturer's protocols. cDNA synthesis for both mRNA and miRNA was performed using a miScript II RT kit (Qiagen). Quantitative real-time PCR was performed using a miScript SYBR Green PCR kit (Qiagen) for miR-153 or an SYBR Green PCR Master Mix (Life Technologies, Frederick,

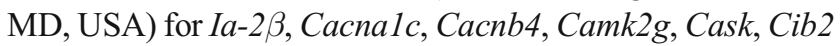
and Gapdh (primer sequences are available in ESM Table 1), and analysed on a 7500 Real-Time PCR system (Life Technologies).

Generation of Cacnalc 3'UTR reporter construct The method for constructing the wild-type (WT) and mutant luciferase reporter plasmids for miRNA target validation was adapted from a previous report [19]. After sequencing validation, plasmid DNA was prepared using a Plasmid Miniprep kit (Qiagen). For further details, see ESM Methods.

Transfection and luciferase reporter assays 293T cells were co-transfected with luciferase reporter plasmids (either a WT or mutant plasmid) and miR-153 mimic (Qiagen) or the scramble control (Qiagen), and the Renilla luciferase control vector (Promega, Madison, WI, USA), using Lipofecatamine 2000 (Life Technologies) according to the manufacturer's instructions. The luciferase activity assay was performed $24 \mathrm{~h}$ after transfection, using the Dual-Luciferase Reporter Assay System (Promega). Firefly luciferase activity was normalised to Renilla luciferase activity.

Target protector functional analysis miR-153 miScript target protector (miR-153-Cacnalc) was designed to be complementary to the predicted miR-153 binding site in the Cacnalc 3'UTR (Qiagen). Transfection was performed according to the manufacturer's protocol. GSIS was performed $72 \mathrm{~h}$ later, together with quantitative real-time PCR for Cacnalc mRNA to assess the protective effect of the target protector. For further details, see ESM Methods.

Calcium microfluorimetry $\left[\mathrm{Ca}^{2+}\right]_{\mathrm{i}}$ was measured using the ratiometric dye fura-2/AM (a high affinity, intracellular calcium indicator), with procedures modified from a previous report [20]. For further details, see ESM Methods.

Protein extraction and western blot analysis Proteins from cells or mouse tissues were isolated and then analysed by western blotting according to standard procedures. See ESM Methods for further details. Rabbit-anti-calcium channel, voltage-dependent, L type, $\alpha 1 \mathrm{C}$ subunit (CACNA1C) antibody (1:500 dilution, Santa Cruz Biotech, Dallas, TX, USA) and mouse-anti- $\alpha$-tubulin antibody (1:5,000 dilution, Abcam, Cambridge, MA, USA) were employed as primary antibodies. Blots were quantified using NIH Image J Software.

Statistical analysis Unless stated otherwise, each experiment was performed three times $(n=3)$ and assayed in triplicate. Data are expressed as the mean \pm SEM of the three experiments. The Student's $t$ test for two groups or ANOVA for multiple groups were used to determine statistical significance. In all cases, $p<0.05$ was considered significant.

\section{Results}

The effect of miR-153 on insulin and dopamine secretion To evaluate the effect of miR-153 on insulin secretion, we used the mouse insulin-secreting cell line MIN6 and freshly isolated pancreatic islets from mice. Cells were transfected with a miR-153 mimic or inhibitor (ESM Fig. 1a, b) and analysed for GSIS and PSIS. Transfection of MIN6 cells with a miR-153 mimic, followed by glucose stimulation, led to a $25 \%$ reduction in insulin secretion. In contrast, miR-153 inhibitor led to a $30 \%$ increase in insulin secretion following glucose stimulation (Fig. 1a). Similar results were obtained using freshly isolated mouse islets (Fig. 1b). Stimulation with high potassium led to a $40-50 \%$ reduction in insulin secretion in the miR-153 mimic group and a 20-30\% increase in insulin secretion in the miR-153 inhibitor group (Fig. 1c, d, respectively). These results clearly show that overexpression of miR-153 suppressed both GSIS and PSIS, whereas inhibition of endogenous miR-153 function enhanced insulin secretion.

Based on the high endogenous expression of miR-153 in brain and the role of its host genes in neurotransmitter secretion, we hypothesised that miR-153 would also play a role in the secretion of neurotransmitters. To test this hypothesis, we overexpressed or inhibited miR-153 in PC12 cells (ESM Fig. 1c), a dopamine-secreting cell line, and measured dopamine secretion. PC12 cells transfected with miR-153 mimic, followed by potassium stimulation, led to a $15 \%$ reduction in dopamine secretion, whereas PC12 cells transfected with miR-153 inhibitor, followed by potassium stimulation, led to a 20\% increase in dopamine secretion (Fig. 1e). Stimulation of PC12 cells with both potassium and the protein kinase C (PKC) stimulator PMA [21], led to a 20\% decrease in dopamine secretion in the miR-153 mimic group and $25 \%$ increase in the miR-153 inhibitor group (Fig. 1f). Taken together, these studies show that miR-153 is a negative regulator of both insulin and dopamine secretion.

GSIS occurs through the closure of ATP-sensitive K channels in the beta cell plasma membrane, resulting in cell depolarisation, activation of voltage-dependent calcium channels (VDCC) and a rise in islet $\left[\mathrm{Ca}^{2+}\right]_{\mathrm{i}}$. In order to ascertain whether miR-153 regulates the activity of VDCCs, we used 
a

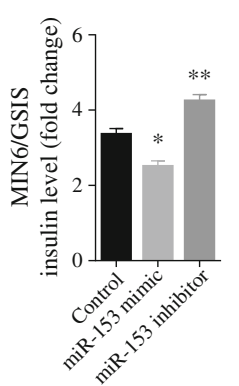

b

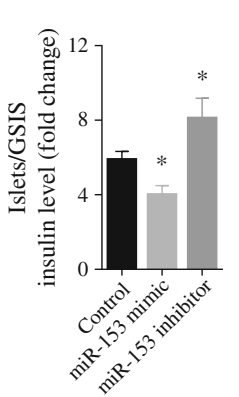

c

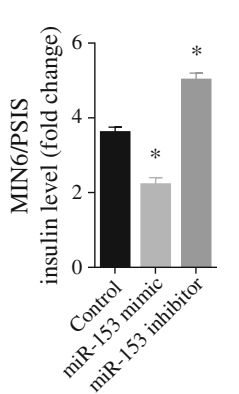

d

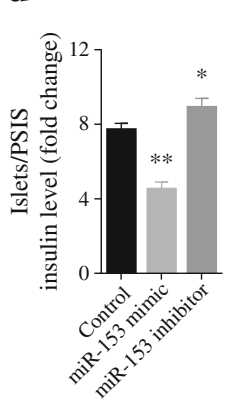

e

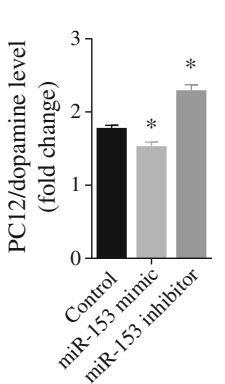

f

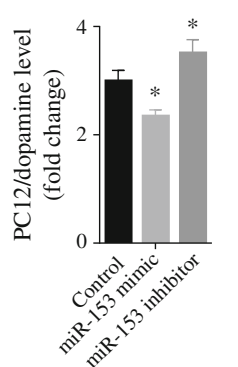

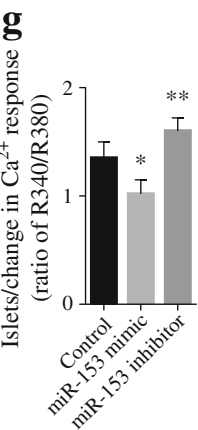

Fig. 1 Impact of miR-153 on insulin and dopamine secretion. After stimulation with $25 \mathrm{mmol} / 1$ glucose $(\mathbf{a}, \mathbf{b})$ or $50 \mathrm{mmol} / 1 \mathrm{KCl}(\mathbf{c}, \mathbf{d})$ in MIN6 cells, or primary mouse islets transfected with scrambled control, miR-153 mimic or miR-153 inhibitor for $72 \mathrm{~h}$, insulin secretion was measured. Data are presented as fold change compared with the level before stimulation. Experiments were performed six times $(n=6)$ in triplicate. (e, f) Dopamine secretion (fold change) in PC12 cells stimulated

FURA2/AM to measure $\mathrm{KCl}$-induced changes in $\left[\mathrm{Ca}^{2+}\right]_{\mathrm{i}}$ in control islets, or islets treated with either the miR-153 mimic or inhibitor. In the current study, we observed that $30 \mathrm{mmol} / \mathrm{l}$ $\mathrm{KCl}$ elicited a robust increase in $\left[\mathrm{Ca}^{2+}\right]_{\mathrm{i}}$ in control islets, and to a larger extent in islets treated with the miR-153 inhibitor (Fig. 1g). Interestingly, the $\left[\mathrm{Ca}^{2+}\right]_{\mathrm{i}}$ response of islets treated with the miR-153 mimic were reduced compared with control islets or to the inhibitor group (Fig. 1g), indicating that miR-153 acts on secretion at least in part by modulating VDCC activity.

Effect of miR-153 on calcium related target genes In order to identify potential targets of miR-153 that could affect insulin and dopamine secretion, the bioinformatics software Targetscan 6.2 and Pictar were employed. Within the list of miR-153 predicted targets, we found 11 calcium related targets. Five targets were identified by both software programs: Cacnalc, Cacnb4, Camk2g, Cask and Cib2. To experimentally validate the prediction, MIN6 cells were transfected with a miR-153 mimic or inhibitor. As seen in Fig. 2a, of the five targets identified, only Cacnalc and Cask had expression levels that were significantly reduced or increased after transfection with miR-153 mimic or miR-153 inhibitor. Given that the Cacnalc gene has been implicated in altering insulin secretion as well as neurotransmitters in vitro and in vivo [22-25], we chose to focus on the Cacnalc gene for further investigation.

Validation of an miR-153 target site in the Cacnalc $3^{\prime}$ UTR To confirm that Cacnalc can be directly regulated by miR-153, a portion of the mouse Cacnalc gene 3'-UTR was cloned into a luciferase reporter vector. A mutated construct was also generated, in which the putative miR-153 binding with $25 \mathrm{mmol} / \mathrm{l} \mathrm{KCl}$ without (e) or with (f) PMA compared with basal levels, $72 \mathrm{~h}$ after transfection with miR-153 mimic or miR-153 inhibitor $(n=3)$. (g) Change in mouse islet $\left[\mathrm{Ca}^{2+}\right]_{\mathrm{i}}$ responses after islet transfection with scrambled controls, miR-153 mimic or miR-153 inhibitor for $72 \mathrm{~h}$, followed by stimulation with $30 \mathrm{mmol} / 1 \mathrm{KCl}$. ${ }^{*} p<0.05$ and ${ }^{* *} p<0.01$ vs controls

site UAUGCAA was mutated into UAgagtA and then cloned into a luciferase reporter vector (Fig. 2b). When compared with the reporter vector alone, luciferase activity was significantly reduced following transient co-transfection of miR-153 mimic with luciferase expression plasmid in 293T cells (Fig. 2c). In contrast, transfection of 293 T cells with scrambled control did not have any effect on the luciferase activity. However, mutations within the seed sequence binding site of Cacnalc abrogated the effect of miR-153 mimic (Fig. 2c), thereby confirming that Cacnalc is a direct target of miR-153.

Regulation of endogenous Cacna1c expression by miR-153 in different cell lines Transfection of cell lines with a miR153 mimic significantly reduced Cacnalc mRNA expression by nearly $50 \%$ as compared with the control in MIN6 cells, normal mouse islets and PC12 cells. In contrast, a significant increase in Cacnalc mRNA expression was observed in all three of these cells following transfection with the miR-153 inhibitor (Fig. 3a-c). Western blot analysis confirmed the effects of miR-153 on the CACNA1C protein level in MIN6 cells and PC12 cells (Fig. $3 \mathrm{~d}, \mathrm{e}$ ). To rule out the possibility that miR-153 was exerting its effect through changes in the expression of its host gene, $I a-2 \beta$, we determined $I a-2 \beta$ mRNA levels following transfection of the different cell lines with either miR-153 mimic or miR-153 inhibitor (Fig. 3f, g). Our results showed that miR-153 has no effect on $I a-2 \beta$ mRNA levels.

Effect of miR-153-Cacnalc target protector To confirm that the reduction of GSIS was due to miR-153 acting through its effect on the Cacnalc gene, a miR-153-Cacnalc target protector was employed. The target protector is a single-stranded modified RNA that is complementary to the miR-153 binding 


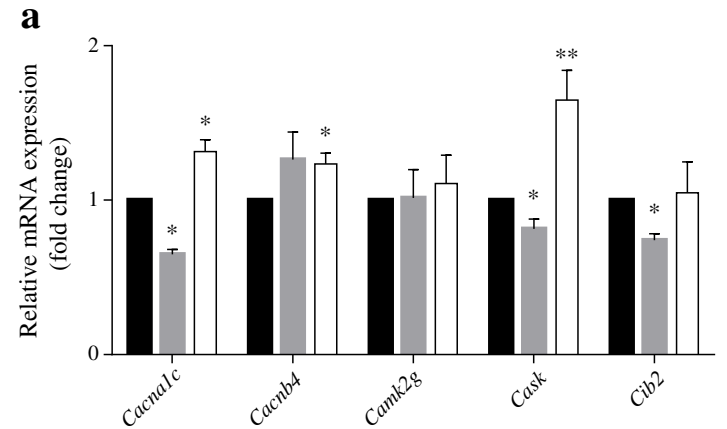

b
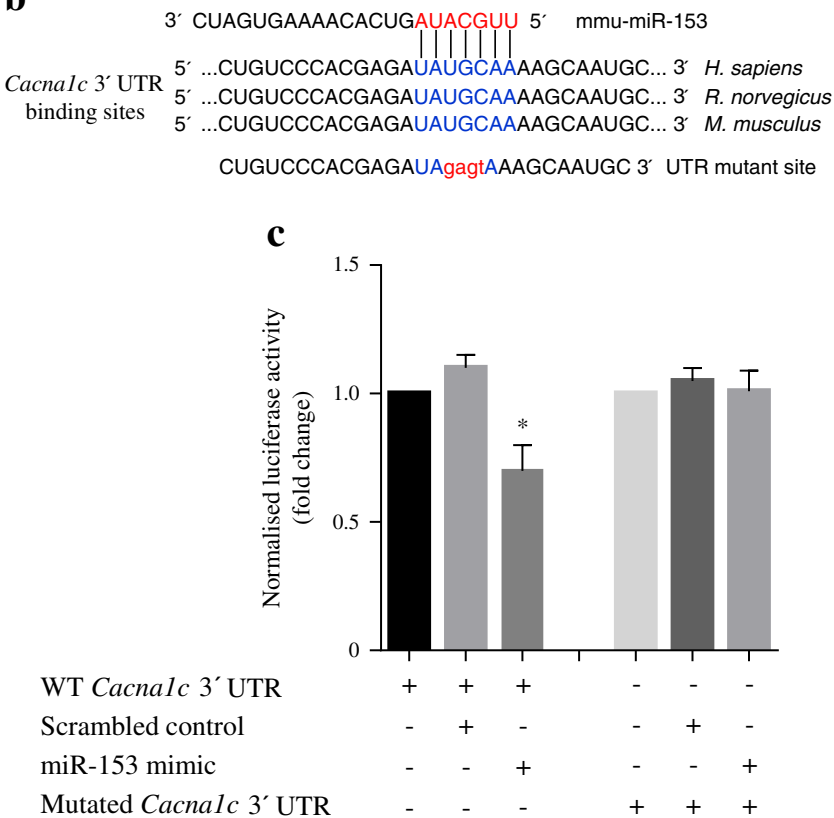

WT Cacnalc 3' UTR Scrambled control miR-153 mimic

Mutated Cacnalc 3' UTR

Fig. 2 Effect of miR-153 mimic or inhibitor on calcium genes: putative miR-153 target site in the Cacnalc 3'-UTR. (a) Expression analysis of miR-153 predicted targets by quantitative real-time PCR $72 \mathrm{~h}$ after transfection with scrambled control (black bars), miR-153 mimic (grey bars) or miR-153 inhibitor (white bars). All data were normalised to Gapdh $(n=3)$. (b) miR-153 predicted target site in mouse Cacnalc 3'-UTR and mutated 3'-UTR sequence with four nucleotide replacements (lower case letters). There is strong sequence conservation in mice, rats and humans. (c) Luciferase reporter assay demonstrating functional activity of miR153 mimic on WT Cacnalc 3'-UTR in 293 T cells, but not on mutated Cacnalc 3'-UTR. Normalised to Renilla luciferase activity $(n=3)$. $*_{p}<0.05$ and ${ }^{*} p<0.01$ vs controls

site on the Cacnalc 3'UTR and specifically disrupts the interaction between miR-153 and Cacnalc 3'UTR. As seen in MIN6 cells (Fig. 4a) and freshly isolated mouse islets (Fig. 4b), transfection with the miR-153-Cacnalc target protector abrogated, at least in part, the suppressive effect of exogenous miR-153 mimic on GSIS. This provides further evidence that the effect of miR-153 mimic on insulin secretion is mediated, at least in part, through Cacnalc gene regulation.
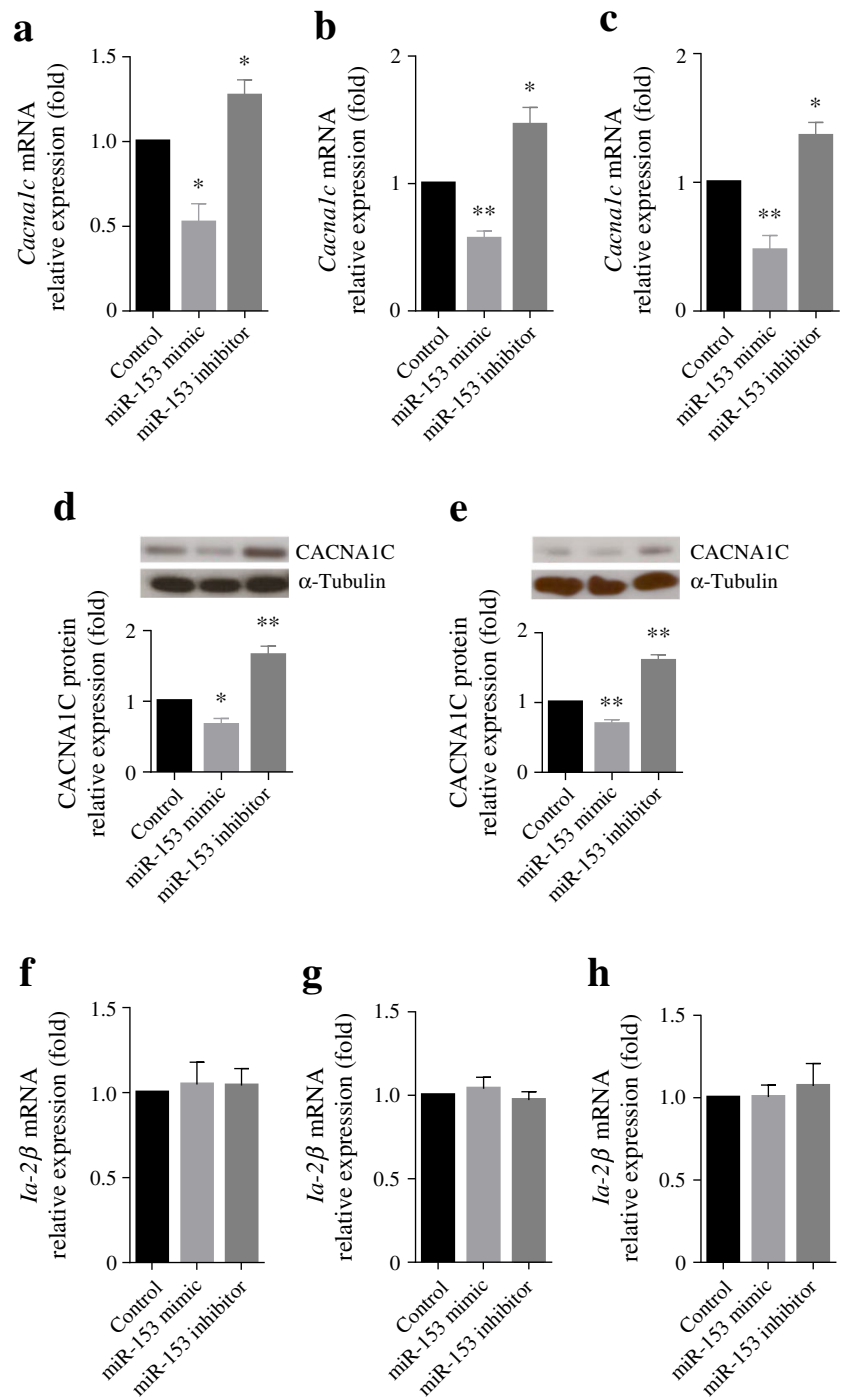

Fig. 3 Regulation of Cacnalc expression by miR-153. Effects of miR-153 mimic and miR-153 inhibitor on Cacnalc expression by quantitative realtime PCR: (a) MIN6 cells; (b) mouse islets; (c) PC12 cells. ( $n=3)$. Western blots for CACNA1C and $\alpha$-tubulin protein levels in MIN6 cells (d) and $\mathrm{PC} 12$ cells $(\mathbf{e})$. The relative expression values were determined by Image J $(n=3)$. Ia- $2 \beta$ mRNA levels were unchanged in MIN6 cells (f), mouse islets (g) and PC12 cells (h) following transfection with miR-153 mimic or inhibitor. $(n=3),{ }^{*} p<0.05$ and ${ }^{* *} p<0.01$ vs controls

To determine the effect of miR-153-Cacnalc target protector on Cacnalc mRNA expression, quantitative real-time PCR was employed. In MIN6 cells (Fig. 4c) and freshly isolated mouse islets (Fig. 4d), co-transfection of cells with miR-153 mimic and miR-153-Cacnalc target protector also abrogated, at least in part, the suppressive effect of exogenous miR-153 mimic on Cacnalc mRNA levels. Although in freshly isolated mouse islets, co-transfection of miR-153 
a

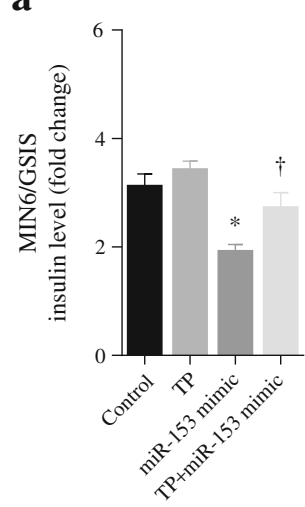

c

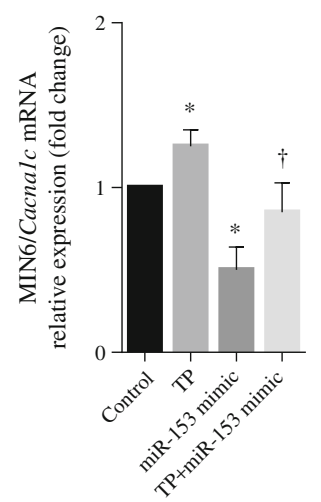

b

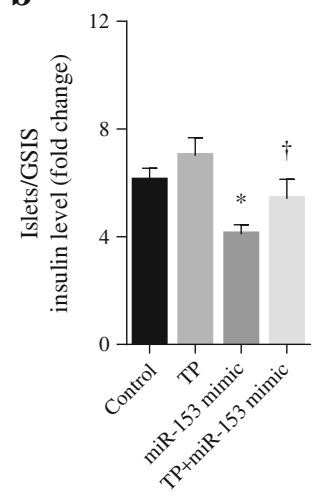

d

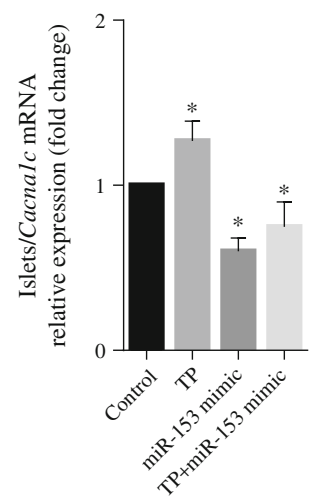

Fig. 4 Effect of miR-153-Cacnalc target protector. Glucose stimulates insulin secretion (fold change) in MIN6 cells (a) and mouse islets (b), after transfection with miR-153 mimic with and without miR-153Cacnalc target protector (TP), showing that the target protector partly abrogated the inhibitory effect of miR-153 on GSIS $(n=3)$. Cacnalc expression analysis by quantitative real-time PCR in MIN6 cells (c) and mouse islets (d) after transfection with miR-153 mimic with and without its target protector. All data were normalised to Gapdh. $n=3,{ }^{*} p<0.05$ vs controls, ${ }^{\dagger} p<0.05$, miR-153 mimic vs $\mathrm{TP}+$ miR-153 mimic

mimic with miR-153-Cacnalc target protector did not fully restore Cacnalc mRNA expression to normal levels, a positive trend was observed (Fig. 4d). The most likely explanation for the failure of the protector to fully restore GSIS is that it is specific to Cacnalc and therefore could not protect the degradation of other potential miR-153 targets involved in secretion.

miR-153 and Cacnalc expression in Ia-2 $\beta$ KO mice To determine whether the expression of Cacnalc is controlled by miR-153 in vivo, Ia-2 $\beta \mathrm{KO}$ and DKO mice, in which miR-153 levels are dramatically reduced [15], were used for expression correlation analysis. Our results showed that miR-153 levels are dramatically reduced in pancreatic islets from $I a-2 \beta \mathrm{KO}$ and DKO mice (Fig. 5a) and also-although

to a lesser extent - in the brain from these mice (Fig. 5b). These observations are consistent with previous studies [15]. In contrast, miR-153 levels remain unchanged in pancreatic islets and brain from $I a-2 \mathrm{KO}$ mice, thus supporting the idea that in mice miR-153 is only expressed from Ia-2 $\beta$. Based on this information, we speculated that Cacnalc mRNA would be elevated in islets and brains from Ia- $2 \beta \mathrm{KO}$ and DKO mice due to low expression of miR-153, but would not be elevated in Ia-2 KO mice. As anticipated, we found a significant increase in Cacnalc mRNA (Fig. 5c, d) and protein (Fig. 5e, f) in both the islets and brain of $I a-2 \beta \mathrm{KO}$ and DKO mice, whereas no obvious change was observed in Ia-2 $\mathrm{KO}$ mice (Fig. 5c-f). These findings support the contention that the expression of Cacnalc in vivo is regulated, at least in part, by miR-153.

\section{Discussion}

Previously we showed that the knockout of the DCV transmembrane genes, $I a-2$ and $I a-2 \beta$ in mice, led to a decrease in the number of DCVs and resulted in a decrease in the secretion of hormones and neurotransmitters [3, 7, 10-12]. This in turn results in a variety of pathophysiological changes including glucose intolerance, female infertility, learning and behavioural disorders and dysregulation of circadian rhythm $[3,7,9-11,14]$. The present experiments add support to previous studies that showed that the knockout of $I a-2 \beta$, but not $I a-2$, results in a decrease in miR-153, which is embedded in intron 19 of the $I a-2 \beta$ gene [15]. The current experiments also show that miR-153 mimics suppress hormone and neurotransmitter (e.g. insulin and dopamine) secretion, whereas miR-153 inhibitors enhance hormone and neuroendocrine secretion.

Since miRNA function is mediated through its effect on a specific set of target genes, we undertook a bioinformatics search to identify miR-153 predicted target genes that might play a role in secretion. Our search identified 11 calcium channel related genes. Five of these gene targets were common in the two different prediction software algorithms that we used. Validation experiments in MIN6 cells confirmed the effect of miR-153 on the endogenous levels of two of these target genes, Cacnalc and Cask.

We focused on Cacnalc because of its well-known involvement in secretion and found that miR-153 mimic downregulated the expression of Cacnalc mRNA and protein, whereas miR-153 inhibitor upregulated the expression of Cacnalc mRNA and protein in MIN6 cells, normal mouse islets and dopamine-secreting $\mathrm{PC} 12$ cells. Thus, there is a complex relationship between IA- $2 \beta$ and miR-153. 

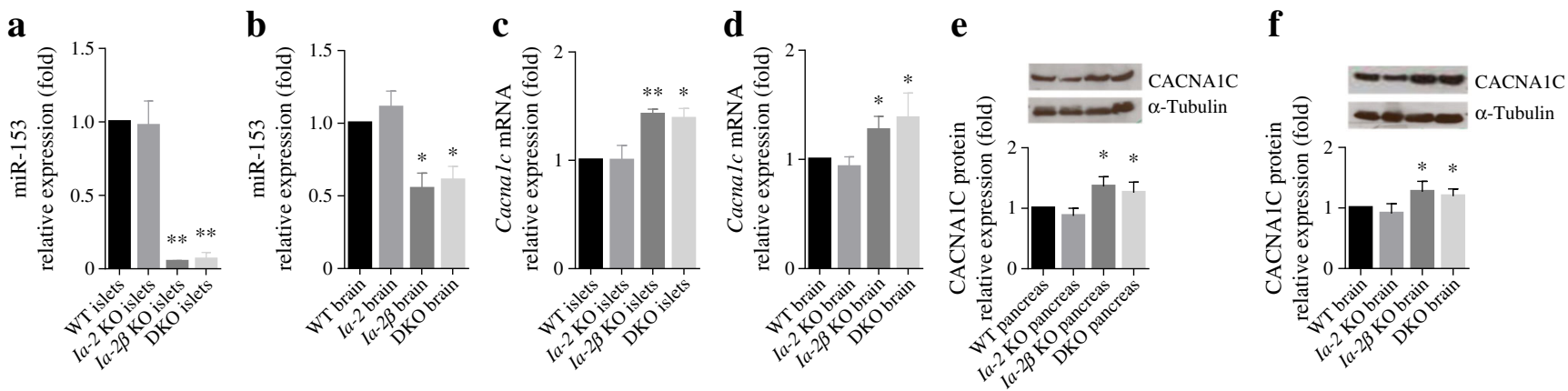

Fig. 5 miR-153 and Cacnalc expression in Ia-2 $\beta$ KO mice. Quantitative real-time PCR analysis of miR-153 levels $(\mathbf{a}, \mathbf{b})$ and Cacnalc mRNA (c, d) in brain and islets from WT, Ia-2 KO,Ia-2 $\beta \mathrm{KO}$ and DKO mice, normalised to Gapdh. (e, f) CACNA1C expression was determined by

western blot in pancreas and brain from WT, Ia-2 KO, Ia-2 $\beta \mathrm{KO}$ and DKO mice. The relative expression values were determined by Image $\mathrm{J}$. $n=5,{ }^{*} p<0.05$ and $* * p<0.01$ vs controls

Hormone exocytosis and neurotransmitter release are fundamental cell biology processes and their regulation is essential for maintaining normal islet and brain function. The release of insulin and dopamine is tightly regulated and dependent on calcium entering cells following cell membrane depolarisation, with subsequent activation of voltage-gated calcium channels [24-28]. Cacnalc is a well-studied gene. The global knockout of Cacnalc in mice results in death at birth [29], whereas beta cellspecific Cacnalc knockout does not result in death, but does result in strong inhibition of GSIS [23]. Other studies have shown that CACNA1C is physically coupled to a number of vesicle-release machinery proteins including the Rab3-interacting molecules (RIMs), Snap-25 and Syntaxin-1 [30]. Interestingly, Snap 25 and Syntaxin-1 also are predicted targets of miR-153 [15, 31]. To determine the in vivo importance of this microRNA on the secretion of insulin and dopamine, specific knockout or overexpression of miR-153 in mice is required. The development of these knockout and transgenic mice is underway in our laboratory, but the already existing $I a-2 \beta$ knockout mice may provide some clues as to what to expect. The $I a-2 \beta$, but not the Ia-2, knockout mice, showed a significant decrease of miR-153 and a significant increase of both

Cacnalc mRNA and protein in the islets and brain. Thus, it is not unreasonable to expect an increase of CACNA1C in vivo following the specific knockout of miR-153. However, this prediction must be viewed with caution since miR-153 targets a number of genes unrelated to calcium channel genes which could directly or indirectly affect secretion.

Although in the current study we focused on the role of miR-153 on insulin and dopamine secretion, miR-153 has been shown to both suppress and enhance tumour growth and play a role in cell proliferation, migration and invasion [32-37]. In addition, miR-153 is dysregulated in some cases of Parkinson's disease and Alzheimer's disease where it affects the expression of several disease-related targets such as $\alpha$-synuclein, amyloid precursor protein and amyloid precursor-like protein 2 [38-41].

In conclusion, stimulation of the $I a-2 \beta$ gene increases both IA-2 $\beta$ protein and miR-153 expression (Fig. 6). The increase in IA- $2 \beta$ protein increases the number of DCV and in turn neuroendocrine secretion $[3,7,10,42]$. In contrast, the increase in miR-153, which is a negative regulator, decreases Cacnalc expression and in turn suppresses neuroendocrine secretion. Thus, IA- $2 \beta$ and miR-153 have opposite functional effects on the secretory pathway.

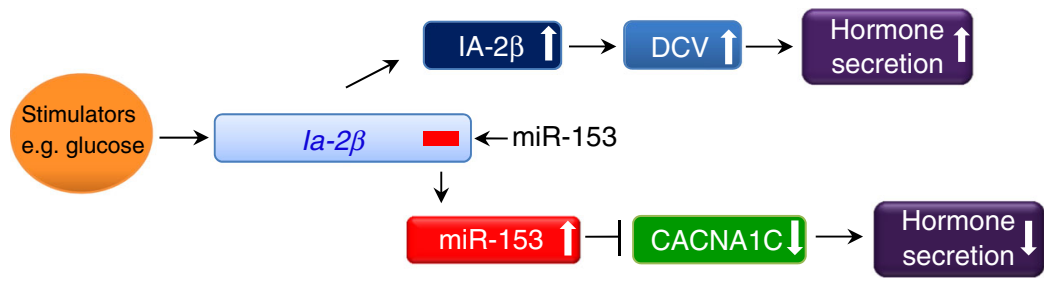

Fig. 6 Model illustrating the dual, but opposite, effects on secretion resulting from the stimulation of both the $I a-2 \beta$ gene and the expression of its intronic microRNA, miR-153. The increase in IA-2 $\beta$ protein facilitates secretion by increasing the number of DCV, whereas an increase in the expression of miR-153, a negative regulator, decreases secretion by inhibiting the expression of calcium channel gene, Cacnalc 
Acknowledgements The authors thank T. Cai (NIDCR, NIH, Bethesda, MD, USA) for his advice and meaningful discussions.

Funding This work was supported by the Intramural Research Program of the NIDCR, NIH, Bethesda, MD, USA. Research in LSS's lab is funded by RO1DK46409.

Duality of interest The authors declare that there is no duality of interest associated with this manuscript.

Author contributions HYX carried out the study design, acquisition and analysis of the data, and drafting of the manuscript. LA, GNC and $\mathrm{S} \mathrm{V}$ performed data acquisition and analysis and contributed to writing the manuscript. ALN and LSS were responsible for the conception and design of the study, acquisition and analysis of the data, and drafting of the manuscript. ALN is the guarantor of this work. All authors were involved in the discussion and revision of the manuscript, and approved the final version to be published.

\section{References}

1. Notkins AL, Lernmark A (2001) Autoimmune type 1 diabetes: resolved and unresolved issues. J Clin Invest 108:1247-1252

2. Solimena M, Dirkx R, Hermel JM et al (1996) ICA 512, an autoantigen of type I diabetes, is an intrinsic membrane protein of neurosecretory granules. EMBO J 15:2102-2114

3. Nishimura T, Kubosaki A, Ito Y, Notkins AL (2009) Disturbances in the secretion of neurotransmitters in IA-2/IA-2beta null mice: changes in behavior, learning and lifespan. Neuroscience 159: 427-437

4. Gomi H, Kubota-Murata C, Yasui T, Tsukise A, Torii S (2013) Immunohistochemical analysis of IA-2 family of protein tyrosine phosphatases in rat gastrointestinal endocrine cells. J Histochem Cytochem 61:156-168

5. Takeyama N, Ano Y, Wu G et al (2009) Localization of insulinoma associated protein 2, IA-2 in mouse neuroendocrine tissues using two novel monoclonal antibodies. Life Sci 84:678-687

6. Caromile LA, Oganesian A, Coats SA, Seifert RA, Bowen-Pope DF (2010) The neurosecretory vesicle protein phogrin functions as a phosphatidylinositol phosphatase to regulate insulin secretion. J Biol Chem 285:10487-10496

7. Cai T, Hirai H, Zhang G et al (2011) Deletion of Ia-2 and/or Ia-2beta in mice decreases insulin secretion by reducing the number of dense core vesicles. Diabetologia 54:2347-2357

8. Kim SM, Theilig F, Qin Y et al (2009) Dense-core vesicle proteins IA- 2 and IA- $2 \beta$ affect renin synthesis and secretion through the $\beta$ adrenergic pathway. Am J Physiol Ren Physiol 296:F382-F389

9. Kubosaki A, Nakamura S, Notkins AL (2005) Dense core vesicle proteins IA-2 and IA-2beta: metabolic alterations in double knockout mice. Diabetes 54(Suppl 2):S46-S51

10. Kubosaki A, Gross S, Miura J et al (2004) Targeted disruption of the IA-2beta gene causes glucose intolerance and impairs insulin secretion but does not prevent the development of diabetes in NOD mice. Diabetes 53:1684-1691

11. Saeki K, Zhu M, Kubosaki A, Xie J, Lan MS, Notkins AL (2002) Targeted disruption of the protein tyrosine phosphatase-like molecule IA- 2 results in alterations in glucose tolerance tests and insulin secretion. Diabetes 51:1842-1850

12. Kubosaki A, Nakamura S, Clark A, Morris JF, Notkins AL (2006) Disruption of the transmembrane dense core vesicle proteins IA-2 and IA-2beta causes female infertility. Endocrinology 147:811-815
13. Carmona GN, Nishimura T, Schindler CW, Panlilio LV, Notkins AL (2014) The dense core vesicle protein IA-2, but not IA-2beta, is required for active avoidance learning. Neuroscience 269:35-42

14. Kim SM, Power A, Brown TM et al (2009) Deletion of the secretory vesicle proteins IA-2 and IA-2beta disrupts circadian rhythms of cardiovascular and physical activity. FASEB J 23:3226-3232

15. Mandemakers W, Abuhatzira L, Xu H et al (2013) Co-regulation of intragenic microRNA miR-153 and its host gene Ia- 2 beta: identification of miR-153 target genes with functions related to IA-2beta in pancreas and brain. Diabetologia 56:1547-1556

16. Kim VN, Han J, Siomi MC (2009) Biogenesis of small RNAs in animals. Nat Rev Mol Cell Biol 10:126-139

17. Baskerville S, Bartel DP (2005) Microarray profiling of microRNAs reveals frequent coexpression with neighboring miRNAs and host genes. RNA 11:241-247

18. Gao X, Qiao Y, Han D, Zhang Y, Ma N (2012) Enemy or partner: relationship between intronic micrornas and their host genes. IUBMB life 64:835-840

19. Nicolas FE (2011) Experimental validation of microRNA targets using a luciferase reporter system. Methods Mol Biol 732:139-152

20. Nunemaker CS, Zhang M, Wasserman DH et al (2005) Individual mice can be distinguished by the period of their islet calcium oscillations: is there an intrinsic islet period that is imprinted in vivo? Diabetes 54:3517-3522

21. Nishimura T, Harashima S, Yafang H, Notkins AL (2010) IA-2 modulates dopamine secretion in PC12 cells. Mol Cell Endocrinol 315:81-86

22. Nitert MD, Nagorny CL, Wendt A, Eliasson L, Mulder H (2008) $\mathrm{CaV} 1.2$ rather than CaV1.3 is coupled to glucose-stimulated insulin secretion in INS-1 832/13 cells. J Mol Endocrinol 41:1-11

23. Schulla V, Renstrom E, Feil R et al (2003) Impaired insulin secretion and glucose tolerance in beta cell-selective $\mathrm{Ca}(\mathrm{v}) 1.2 \mathrm{Ca} 2+$ channel null mice. EMBO J 22:3844-3854

24. Mortensen OV (2013) MKP3 eliminates depolarization-dependent neurotransmitter release through downregulation of L-type calcium channel Cav1.2 expression. Cell Calcium 53:224-230

25. Hofmann F, Flockerzi V, Kahl S, Wegener JW (2014) L-type $\mathrm{CaV} 1.2$ calcium channels: from in vitro findings to in vivo function. Physiol Rev 94:303-326

26. Gaisano HY (2014) Here come the newcomer granules, better late than never. Trends Endocrinol Metab 25:381-388

27. Sudhof TC (2012) Calcium control of neurotransmitter release. Cold Spring Harb Perspect Biol 4:a011353

28. Rorsman P, Braun M, Zhang Q (2012) Regulation of calcium in pancreatic alpha- and beta-cells in health and disease. Cell Calcium 51:300-308

29. Seisenberger C, Specht V, Welling A et al (2000) Functional embryonic cardiomyocytes after disruption of the L-type alpha1C (Cav1.2) calcium channel gene in the mouse. J Biol Chem 275: 39193-39199

30. Gandini MA, Felix R (2012) Functional interactions between voltage-gated $\mathrm{Ca}(2+)$ channels and Rab3-interacting molecules (RIMs): new insights into stimulus-secretion coupling. Biochim Biophys Acta 1818:551-558

31. Wei C, Thatcher EJ, Olena AF et al (2013) miR-153 regulates SNAP-25, synaptic transmission, and neuronal development. PLoS One 8:e57080

32. Anaya-Ruiz M, Cebada J, Delgado-Lopez G, Sanchez-Vazquez ML, Perez-Santos JL (2013) miR-153 silencing induces apoptosis in the MDA-MB-231 breast cancer cell line. Asian Pac J Cancer Prev 14:2983-2986

33. Wu Z, He B, He J, Mao X (2013) Upregulation of miR-153 promotes cell proliferation via downregulation of the PTEN tumor suppressor gene in human prostate cancer. Prostate 73:596-604

34. Xu Q, Sun Q, Zhang J, Yu J, Chen W, Zhang Z (2013) Downregulation of miR-153 contributes to epithelial- 
mesenchymal transition and tumor metastasis in human epithelial cancer. Carcinogenesis 34:539-549

35. Zhang L, Pickard K, Jenei V et al (2013) miR-153 supports colorectal cancer progression via pleiotropic effects that enhance invasion and chemotherapeutic resistance. Cancer Res 73:6435-6447

36. Yuan Y, Du W, Wang Y et al (2015) Suppression of AKT expression by miR-153 produced anti-tumor activity in lung cancer. Int $\mathrm{J}$ Cancer 136:1333-1340

37. Shan N, Shen L, Wang J, He D, Duan C (2015) MiR-153 inhibits migration and invasion of human non-small-cell lung cancer by targeting ADAM19. Biochem Biophys Res Commun 456:385-391

38. Liang $\mathrm{C}, \mathrm{Zhu} \mathrm{H}, \mathrm{Xu} \mathrm{Y}$ et al (2012) MicroRNA-153 negatively regulates the expression of amyloid precursor protein and amyloid precursor-like protein 2. Brain Res 1455:103-113
39. Doxakis E (2010) Post-transcriptional regulation of alpha-synuclein expression by mir-7 and mir-153. J Biol Chem 285:12726-12734

40. Long JM, Ray B, Lahiri DK (2012) MicroRNA-153 physiologically inhibits expression of amyloid-beta precursor protein in cultured human fetal brain cells and is dysregulated in a subset of Alzheimer disease patients. J Biol Chem 287:31298-31310

41. Kim HJ, Park G, Jeon BS, Park WY, Kim YE (2013) A mir-153 binding site variation in SNCA in a patient with Parkinson's disease. Mov Disord 28:1755-1756

42. Harashima S, Clark A, Christie MR, Notkins AL (2005) The dense core transmembrane vesicle protein IA-2 is a regulator of vesicle number and insulin secretion. Proc Natl Acad Sci U S A 102:8704 8709 